\title{
CORRESPONDÊNCIA ENTRE ROSA E BIZZARRI: O DEBATE SOBRE A TRADUÇÃO DO “COCO DE FESTA DO CHICO BARBÓZ"
}

\author{
Claudia Soares ${ }^{1}$ \\ Márcia Regina Jaschke Machado ${ }^{1}$ \\ ${ }^{1}$ Universidade Federal de Minas Gerais, Belo Horizonte, Minas Gerais, Brasil
}

Resumo: A correspondência entre Guimarães Rosa e seu tradutor italiano, Edoardo Bizzarri, evidencia um relacionamento amigável e cordial, até mesmo afetuoso, marcado pela admiração mútua. Rosa frequentemente elogia e estimula Bizzarri na difícil empreitada de traduzir Corpo de baile, tarefa a que se dedicava naquele momento. Cria-se, assim, um ambiente agradável e propício à discussão das ideias. As cartas trocadas entre autor e tradutor são muito esclarecedoras em relação a vários aspectos de Corpo de baile e da obra rosiana em geral, o que faz dessa correspondência importante documento, não só para o conhecimento dos processos de tradução, mas também para o estudo da obra do autor mineiro. É o que se revela no longo debate que travam autor e tradutor acerca da inclusão ou não, na edição italiana, do "Coco de festa do Chico Barbós", uma das epígrafes de Corpo de baile. Neste trabalho, acompanhamos essa discussão, que fornece informações preciosas para se pensar as tão propaladas relações entre a cultura popular e a chamada alta cultura na obra de Guimarães Rosa.

Palavras-Chave: Correspondência Guimarães Rosa - Edoardo Bizzarri; Relação Cultura Popular/Cultura Erudita em Guimarães Rosa; Epígrafes de Corpo de baile 


\title{
CORRESPONDENCE BETWEEN ROSA AND BIZZARRI: THE DEBATE ABOUT THE TRANSLATION OF "COCO DE FESTA DO CHICO BARBÓZ"
}

\begin{abstract}
The correspondence between Guimarães Rosa and his Italian translator, Edoardo Bizzarri, reveals a kind and friendly, even affectionate, relationship, marked by mutual admiration. Rosa frequently praises and encourages Bizzarri in the hard enterprise of translating Corpo de baile, a task to which he was dedicated at the time. They thus create a pleasant environment, contributing to the discussion of ideas. The letters exchanged between author and translator are very enlightening in relation to several aspects of Corpo de baile and the Rosean work in general, making this correspondence an important document, not only to the knowledge of translation processes, but also to the study of the author's work. This is what stands out in their discussion about whether or not to include in the Italian edition the passage called "Coco de festa do Chico Barbós", one of Corpo de baile's epigraphs. In this paper we focus on this discussion, which provides precious information to reflect on the widely spoken of relations between popular culture and high culture in the work of Guimarães Rosa.
\end{abstract}

Keywords: Correspondence Guimarães Rosa - Edoardo Bizzarri; Relation Popular Culture/High Culture in Guimarães Rosa; Epigraphs of Corpo de baile

Guimarães Rosa e Edoardo Bizzarri tiveram um único encontro pessoal, em 1957, na noite em que o autor de Grande sertão: veredas recebeu o Prêmio Carmen Dolores Barbosa, de cujo júri o tradutor participava. ${ }^{1}$ Anos depois desse encontro, Bizzarri aceitaria o convite de Guimarães Rosa para traduzir as novelas de Corpo de baile. $\mathrm{O}$ relacionamento entre os dois ficou praticamente restrito à troca epistolar, a qual viabilizou o diálogo sobre o processo de tradução e tornou-se importante documento que mostra a atuação de ambos ao longo desse processo. A correspondência teve início em 1959, mas foi motivada pela versão para o italiano do conto "Duelo", de Sagarana, nos números VI e VII do Il Progresso

${ }^{1}$ Cf. Bizzarri; Rosa, 1981, p.3. 
Ítalo-Brasiliano, periódico que começara a circular em São Paulo. Bizzarri foi, assim, quem escreveu a primeira carta, na qual pedia autorização para traduzir o conto. Em 5 de outubro de 1959, Rosa remeteu-lhe o agradecimento pela tradução:

Aqui estou, porém, festiva e sinceramente, para lhe agradecer a forte alegria que me deu, com o envio dos números do 'Progresso Ítalo-Brasileiro' com o nosso 'Duelo'. A tradução - de coração o digo - entusiasmou-me, achei-a admirável. Nem sei, nem pensei que fosse possível um trabalho assim. Nada do texto original se evaporou, nada foi omitido, tudo ficou preservado... e prestigiado! E a nota de apresentação, generosa e séria, comoveu-me. Gratíssimo, por tudo.

Com o grato e melhor abraço amigo do seu

Guimarães Rosa (Bizzarri; Rosa, 4, grifo nosso).

A conversa conduzida pelo tom da amabilidade e do entusiasmo, como se pode verificar, foi marca predominante dessa troca epistolar. Cabe destacar também a referência na primeira pessoa do plural ao texto traduzido. De acordo com Berthold Zilly: "Falando na primeira pessoa do plural, [Rosa] estabelece uma parceria entre autor e tradutor, os quais, idealmente, devem cooperar, animados pelos mesmos princípios estéticos." (Zilly, 8). Pelo que se percebe, Rosa procurava valorizar e estimular o trabalho do tradutor, reconhecendo nele não apenas a transposição do texto para o novo idioma, mas a composição de um novo texto, numa espécie de coautoria:

A leitura das cartas com os tradutores mostra que o escritor não apenas respondia com impressionante minúcia ao que lhe era questionado, como também detalhava espontaneamente significados ocultos das obras, desvendando nelas aquilo que chamava de seu sovrassenso: ou seja, o sentido metafísico que intencionalmente escondia sob uma 
descrição da natureza ou o nome de uma personagem. Nada mais nada menos do que uma explicação da essência de suas metáforas, por sua vez a essência de sua poética. Mais do que isso, Rosa apontava caminhos que acreditava serem os corretos para mimetizar nas línguas-alvo os efeitos buscados nos originais, dos quais um dos referidos mais frequentemente era o da indeterminação [...]. (Viotti, 323).

Na edição da correspondência, contudo, uma lacuna de 3 anos separa a missiva de 5 de outubro de 1959 da seguinte, remetida por Bizzarri em 18 de outubro de 1962: "Passaram-se três anos. Em outubro de 1962 E. B. recebeu, inesperadamente, um exemplar de Primeiras Estórias, com a dedicatória: 'A EDOARDO BIZZARRI, com o grato apreço e a viva simpatia do Guimarães Rosa. Rio, Setembro, 62'" (Bizzarri; Rosa, 4). A partir de então, a troca epistolar passou a ser contínua pelos próximos 5 anos, findando em 20 de outubro de 1967, com a carta em que Guimarães Rosa dava notícias sobre sua posse na Academia Brasileira de Letras, marcada para 16 de novembro do mesmo ano. Pouco tempo depois, em 19 de novembro, Rosa morreria de enfarte.

O convite para Bizzarri traduzir Corpo de baile para o italiano foi remetido pelo autor em 21 de novembro de 1962, e a resposta, expedida na sequência, em 3 de dezembro:

Tinha decidido encerrar definitivamente minhas experiências de tradutor. Traduzir é praticar um exercício de estilo, uma pesquisa de interpretação; é, afinal, um ato de amor, pois trata-se de se transferir por inteiro numa outra personalidade. Tendo feito tudo isso com autores como Melville, Henry James, Faulkner, Graciliano Ramos e Guimarães Rosa, confesso que me dava por satisfeito. [...] Tudo certo. Mas aqui chegou a sua carta, acordando a amizade e a vaidade, e, com elas, vaidosas preocupações. Será que Grande sertão: veredas, ou outra obra de Guimarães Rosa, vai cair nas mãos de um tradutor inexperiente, que a estrague mais 
do que é inevitável, ao vertê-la para o italiano? E na luta entre meus velhos problemas e o que se me afigura como dever de amigo, encontro-me numa aflição tremenda. Da qual posso sair só abrindo o coração à sugestão da amizade e deixando, com a sabedoria da terra, a decisão final ao acaso. Autorizo, portanto, o ilustre Amigo - sempre que o achar oportuno e conveniente - a indicar aos editores italianos meu nome como eventual tradutor [...]. (Bizzarri; Rosa, 7).

Embora tenha apresentado resistência para voltar a fazer traduções, Bizzarri acabou aceitando o trabalho, segundo ele mesmo, por amizade. O que foi recebido com entusiasmo pelo autor das novelas:

Sério, sincero: sua carta me alegrou, fora de conta. Você me promete o que nem me parecia crível. [...] Vou escrever à Feltrinelli ('Corpo de Baile'); com calma, vou escrever à Mondadori ('Grande Sertão: Veredas' - ?). Fiquemos, porém, desde já, unidos, combinados, inseparados. (Bizzarri; Rosa, 8. 25/01/1963).

Cabe aqui destacar o posicionamento de Guimarães Rosa, que procurou externar a euforia como demonstração da conquista do tradutor ideal, ao mesmo tempo em que propôs um acordo, no qual remetente e destinatário permanecessem unidos durante o processo de tradução. Percebe-se, assim, o interesse do autor em acompanhar o trabalho do tradutor e sua disposição para auxiliá-lo. O acordo foi aceito por Bizzarri, e, a partir desse momento, os interlocutores passaram a fazer da troca epistolar o espaço para discussões, questionamentos e ajustes sobre a construção do texto no novo idioma.

Ambos buscaram estabelecer, desde então, um ambiente propício à exposição de seus posicionamentos por meio das cartas, o que 
seria muito importante para a troca de ideias sobre o processo de tradução que se iniciava. Como explica Angela de Castro Gomes:

[...] tal como outras práticas de escrita de si, a corre-
spondência constitui simultaneamente o sujeito e seu texto.
Mas, diferentemente das demais, a correspondência tem
um destinatário específico com quem se vai estabelecer
relações. Ela implica uma interrelação, uma troca, sendo
um jogo interativo entre quem escreve e quem lê - sujeitos
que se revezam, ocupando os mesmos papéis através do
tempo. Escrever cartas é assim 'dar-se a ver', é mostrar-
se ao destinatário, que está ao mesmo tempo sendo 'visto'
pelo remetente, o que permite um tête-à-tête, uma forma
de presença (física, inclusive) muito especial. (Gomes, 19).

É o que se percebe, portanto, na correspondência de Rosa e Bizzarri. Nesse processo dialógico, ambos tiveram o cuidado de estabelecer uma relação pautada no afeto e na expressão de admiração mútua, um facilitador para a exposição dos questionamentos do tradutor e as sugestões do escritor: "Sempre volto a admirar, profundamente grato, sua pasmosa tradução de 'Duelo' - que parece mesmo não existir, de tão incrível. Traduzir para o italiano, sei que é das proezas mais difíceis, é idioma que 'aceita pouco' [...]. E mesmo assim, a façanha se fez." (Bizzarri; Rosa, 5. 21/11/1962).

Termos como "amigo" e "amizade" são recorrentes nessas missivas, bem como as declarações de respeito ao trabalho de ambos. O diálogo pautado na afetividade pode ser entendido, assim, como uma estratégia para que os interlocutores se sintam à vontade para expor seus pontos de vista, aspecto recorrente nas correspondências de intelectuais, como observa Mônica Pimenta Velloso:

[...] árduo diálogo entre o impulso dos sentimentos e o movimento da razão ordenadora; a percepção da amizade

${ }^{2}$ Carta de Guimarães Rosa, de 21 de novembro de 1962.

Cad. Trad., Florianópolis, v. 41, no 2 p. 292-308, mai-ago, 2021. 
entra aí elegendo, forjando e organizando as linhas de debate. A ideia de que entre amigos 'tudo deve ser dito' funciona como desafio e mote inspirador. ${ }^{3}$ (Velloso, 212).

Ao mesmo tempo, é importante não se perder de vista que a construção dessa relação baseada na afetividade aproxima-se da questão da mise en scène de que nos fala Alain Pagès: "[...] la correspondance, contrairement à ce qu'on croit, n'est pas toujours le lieu d'un engagement sincère: c'est une mise en scène. Ce qui s'écrit, s'écrit sous le regard de l'Autre, et les actes ne suivent pas les mots." (Pagès, 209). Assim, é possível verificar que há na escrita epistolar a formação de uma imagem que cada interlocutor faz de si perante o outro, com a finalidade de persuasão. Embora sejam evidentes o respeito e a admiração que nutriram um pelo outro, essas cartas testemunham as estratégias de elaboração de discursos que viabilizassem a exposição de seus posicionamentos nesse processo de argumentações e convencimento. Como suporte que supre a impossibilidade de encontro pessoal, substitutas da conversa tête-à-tête, as cartas podem ser entendidas, antes de tudo, como um veículo de fala portadora de ideias com que se argumenta e contra-argumenta. Nesse sentido, elas se tornam fundamentalmente um espaço de exercício político. Em primeiro lugar, um remetente escolhe um destinatário. Em seguida, discorre sobre uma série de assuntos, esperando um posicionamento da outra parte. A partir daí são estabelecidos diálogos, tentativas de entendimentos entre os interlocutores. (Machado, 2012)

\footnotetext{
${ }^{3}$ Em referência, nesse caso, à correspondência de Mário de Andrade.

4 " [...] a correspondência, ao contrário do que se acredita, nem sempre é o lugar de um compromisso sincero: é uma encenação. O que está escrito, está escrito sob o olhar do outro, e os atos não seguem as palavras". A questão da encenação na escrita epistolar é frequentemente apontada por Marcos Antonio de Moraes em seus trabalhos. Além disso, Mônica Pimenta Velloso e Júlio Castañon Guimarães fazem apontamentos relevantes sobre essa questão, respectivamente, em: Velloso, 205-224, e Guimarães, 2004.
} 
O 'comungar' da carta se espelha no desejo de estar junto [...], na constante troca de opinião, nas sugestões contestadas ou aceitas. O 'outro', no diálogo epistolar, concorre muitas vezes para a realização artística, funcionando como termômetro da criação. A carta é 'laboratório' onde se acompanha o engendramento do texto literário em filigranas, desvendando-se elementos de constituição técnica da poesia e seus problemas específicos. ${ }^{5}$ Propicia a análise (gênese, busca de sentido) e torna manifesto as motivações externas que 'precisam a circunstância' da criação. A escrita epistolográfica também proporciona a experimentação linguística e o desvendamento confessional. Enquanto expressão do momento, nascida ao correr da pena, os paradoxos e contradições se tornam presentes. Como em um romance, nela também as paixões se entrelaçam e os desejos afloram. ${ }^{6}$ (Moraes, 14).

A mesma condição pode ser verificada na correspondência de Guimarães Rosa e Edoardo Bizzarri. Essa troca epistolar viabilizou, como se vê, a aproximação de ambos e se configurou como espaço onde efetivamente aconteceram as discussões pertinentes à produção do novo texto. Nas cartas estão os bastidores do trabalho conjunto entre autor e tradutor. A título de exemplo, vale recuperar o que disse Bizzarri em carta de 16 de dezembro de 1963: "Obrigado, mais uma vez. A sua paciência é bíblica, e imensa a sua bondade. Como perdoar-me pelo tempo que lhe vou tirando?" (Bizzarri; Rosa, 72). Guimarães Rosa, do outro lado, nunca se furtava à resposta, explicando, muitas vezes, significados de passagens de sua obra ou até mesmo sobre seus processos de composição. Nesse sentido, como sabemos, essas cartas são importantes documentos para pesquisas que focalizem os processos de tradução e também para os estudos de Corpo de Baile e da obra rosiana em geral.

\footnotetext{
${ }^{5}$ No caso de Rosa e Bizzarri, a constituição técnica da tradução.

${ }^{6}$ Nessa passagem, Marcos Antonio de Moraes refere-se à correspondência de Mário de Andrade e Manuel Bandeira, que guarda o debate desses interlocutores sobre seus textos em processo de composição.
} 
A correspondência é chave que abre e desvenda o significado e a composição de muitas de suas criações e construções insólitas, permitindo a leitura de alguns de seus neologismos, indicando as matrizes de provérbios ou frases feitas modificadas, de expressões abreviadas, explicitando a composição de metáforas, metonímias, eufemismos. Como se pode ver, a correspondência auxilia a leitura da obra. É uma leitura determinada pelo próprio autor, que pode não ser a única, visto que a construção textual, como salienta Guimarães Rosa, pode admitir outras leituras que certamente os leitores farão, pelas pistas deixadas pelo autor. Por outro lado, a partir das cartas é também possível pinçar trechos que esboçam elementos para uma poética rosiana. (Nascimento, 171)

No que se refere ao conjunto de sete novelas rosiano, as discussões entre tradutor e escritor sobre as epígrafes do livro, mais especificamente sobre uma delas, chamam a atenção para essa importância. Rosa e Bizzarri discutem longamente acerca da inclusão ou não de uma epígrafe na edição italiana. A discussão entre autor e tradutor demonstra que, apesar da gentileza no trato, da expressão do afeto e dos elogios que faz recorrentemente ao tradutor, Rosa não deixa de argumentar e contra-argumentar com ele, ainda que da forma mais cordial possível, quando suas ideias não são coincidentes. É o que ocorre no que diz respeito à inclusão, na edição italiana, da epígrafe que Rosa intitulou "Coco de festa do Chico Barbós".7 A discussão que os dois travam sobre o assunto fornece, também, informações preciosas para se pensar as tão propaladas relações que se estabelecem na obra de Guimarães Rosa entre cultura popular e o que se costuma chamar de alta cultura, ou cultura erudita.

7 Sobre o nome do "autor" do Coco, a epígrafe ainda diz: "[...] dito Chico Rabeca, dito Chico Precata, Chico do Norte, Chico Mouro, Chico Rita [...]". Em carta de 3 de janeiro de 1964, Rosa explica a multiplicidade de nomes atribuídos ao Chico: "[...] o barroco mistifório de nomes do Chico - denotando nossa absoluta incapacidade em embarcar num só aspecto a personalidade de uma pessoa interessante." (Bizzarri; Rosa, 82). 
Como se sabe, em sua primeira e segunda edições ${ }^{8}$ Corpo de baile apresentava 8 epígrafes: quatro trechos das Enéadas, de Plotino, o filósofo neoplatônico do século III; três de $O$ anel ou a pedra brilhante, de Ruysbroeck, místico brabanção do século XIV; e "Coco de festa do Chico Barbós". Composição de fortíssimo sabor regional, essa última seria um exemplar autêntico da cultura popular da região natal de Guimarães Rosa: segundo o próprio autor, fora ouvido e transcrito por ele da voz de um cantador popular do sertão. (Bizzarri; Rosa, 24. 11/10/ 1963).

A respeito da epígrafe sertaneja de Corpo de baile, Rosa e Bizzarri travam uma longa discussão em sua correspondência. A justaposição de elementos assim tão díspares - de um lado, a alta erudição das citações de ordem místico-metafísicas de Plotino e Ruysbroeck, de outro, a canção oriunda do mundo da cultura popular do sertão - causou estranheza ao tradutor. ${ }^{9}$ Em carta de 6 de outubro de 1963, Bizzarri consulta Rosa sobre a possibilidade de não publicar o Coco na edição italiana e expõe seus motivos:

Eu sugeriria - quanto às citações epigrafando a obra toda - a eliminação (não me xingue) do Coco de festa do Chico Barbós, pois, fatalmente, na tradução em outra língua e para o leitor estrangeiro (que ainda tem de ser introduzido no mundo do sertão) sua aproximação com Plotino e Ruysbroeck perde todo o sabor, sentido e sugestão que pode

\footnotetext{
${ }^{8}$ Bem como, pelo menos, uma edição comemorativa (a de 2006) que tenta recuperar o formato original do livro que, a partir de sua $3^{\text {a }}$ edição, foi desmembrado em 3 . ${ }^{9}$ Esse efeito de estranhamento, entretanto, não se distancia dos objetivos estéticos do autor. Como observou Berthold Zilly, "[E]mbora criticasse os protagonistas da Semana de Arte Moderna de 1922, achando-os muito intelectualizados e cerebrais, Guimarães Rosa no fundo assumiu princípios importantes das vanguardas dos anos 1920, o experimentalismo, a ruptura com tradições linguísticas e literárias, o choque como efeito intencionado, ainda que sem o culto da grande cidade moderna e sem as preocupações políticas. Queria [...] obrigar o público a uma leitura reflexiva e emotiva, inovando constantemente seus procedimentos, evitando termos gastos, chavões, convenções e incitando o leitor ao estranhamento". (Zilly, 8)
} 
apresentar o texto original para o leitor brasileiro. No caso, porém, de $\mathrm{V}$. achar necessária a inclusão do Coco na edição italiana, peço maiores esclarecimentos a respeito dos versos 8 e 10. (Bizzarri; Rosa, 19).

Guimarães Rosa responde concordando com a supressão do Coco, mas somente enquanto epígrafe geral do livro, e sugere que ele seja deslocado para "A estória de Lélio e Lina” ou "Dão-Lalalão"; fornece ainda as informações solicitadas por Bizzarri, sobre os versos 8 e 10 (Bizzarri; Rosa, 20 e 24. 11/10/1963). Bizzarri faz, então, uma primeira versão do Coco em italiano, que submete à aprovação de Rosa e sugere que a peça popular epigrafe "A estória de Lélio e Lina", pois "Lélio também quer das coisas o miúdo e o inteiro, demais." (Bizzarri; Rosa, 36. 30/10/1963). O autor de Corpo de baile responde elogiando muitíssimo a tradução de Bizzarri:

A tradução do COCO saiu fabulosa, formidável, estupenda, incrivel. (Chega a espantar-me e comover-me, ver como V. é severo consigo mesmo.) Não sei, mas V., para mim, cresce a cada momento. Parodio a Bauer: ... 'Se é Bizzarri - é bom'! Você é um mistério. V., em tudo, me permite o puro prazer de admirar. Não há linha, nem coisinha, de sua lavra, que não me dê 'frêmito'. Tenho recebido [...] peças de tradutores meus em francês, italiano, inglês, norte-americano, alemão, 'austríaco', espanhol e 'uruguaio-argentino' (platenho); tudo bom, em geral, mas sem transmitir-me essa imediata sensação de invulnerabilidade e plenitude, de façanha acabada e perfeita, ida ao limite - que é o que V. escreve me traz. E, como isso que digo não é euforia egocêntrica minha, nem lisonja barata, mas constatação sincera, fico pensando. Que predisposição é essa? Alguma espécie de correspondência anímica, ou de igual cumprimento-de-ondas de sensibilidades? Sinto-me com vocação para ser... seu discípulo. (Bizzarri; Rosa, 3637. $06 / 11 / 63)$. 
O elogio ao trabalho do tradutor, que talvez soe um pouco entusiasmado demais, ${ }^{10}$ além de expressar a admiração pelo trabalho de Bizzarri, funciona como um estímulo a esse último, que enfrentava grandes dificuldades para traduzir a peça exótica.

É este o Coco tão caro a Guimarães Rosa:

Da mandioca quero a massa e o beiju,

Do mundéu quero a paca e o tatu;

Da mulher quero o sapato, quero o pé!

- quero a paca, quero o tatu, quero o mundé...

Eu, do pai, quero a mãe, quero a filha:

Também quero casar na família.

Quero o galo, quero a galinha do terreiro, quero o menino da capanga do dinheiro.

Quero o boi, quero o chifre, quero o guampo

Do cumbuco, do balaio, quero o tampo.

Quero a pimenta, quero caldo, quero o molho

- eu do guampo quero o chifre, quero o boi

Qu'é dele, o doido, qu'é dele, o maluco?

Eu quero o tampo do balaio, do cumbuco... (Rosa, Ficção

Completa, 805)

Na carta de 11 de outubro de 1963, em que responde à solicitação de Bizzarri, sobre os versos 8 e $10,{ }^{11}$ Rosa revela o motivo da profunda impressão que lhe causou a composição popular:

\footnotetext{
${ }^{10}$ Mas parece mesmo sincero. Em entrevista a Arnaldo Saraiva, afirma: “[...] gosto das traduções que filtram. Da tradução italiana do Corpo de Baile gosto mais do que do original.” (Saraiva, 116).

${ }^{11}$ Assim Rosa explica "o menino da capanga do dinheiro": "Suponho seja um desses meninos que guiam cegos pedidores de esmola, pelas estradas, e vão guardando numa sacola ou capanga, o dinheirinho arrecadado." Sobre o verso 10, diz que balaio e cumbuco são a mesma coisa: "[...] recipiente de chifre para rapé, etc.” (Bizzarri; Rosa, 24. 11/10/1963).
} 
[...] pela poesia de sua estranha mixórdia, ele me impressionou vivamente. [...] principalmente, traduz ele, de modo cômico aparente, mas cheio de vitalidade, uma ânsia de posse da totalidade, do absoluto, da simultaneidade e plenitude, eternas. O canto, ele mesmo reconhece que os outros, os comuns e medíocres, o tomam por louco. Mas ele, assim mesmo, persiste em querer tudo: o conteúdo e a própria caixa de Pandora - até sua tampa! - e seja ela o que for: balaio ou cumbuco... (Bizzarri; Rosa, 24).

Guimarães Rosa, o sertanejo diplomata, consegue estabelecer uma área de correspondência entre os elementos provindos do mundo hipersofisticado da chamada cultura erudita e os da tradição popular do seu sertão natal; neste caso, o mito de Pandora e o desejo do sujeito que fala no Coco do Chico. A sensibilidade de Rosa, habituada tanto ao mundo da cultura erudita quanto ao da cultura popular do sertão, permite que ele estabeleça, entre os dois universos, associações e pontos de conexão, a partir dos quais pode disseminar pelo texto elementos que sugiram outras possibilidades de significação. Rosa o faz sem hierarquizar os dois universos, como até então era bastante comum na literatura brasileira. Sua disposição afetiva, amorosa, para com o mundo que recriou ficcionalmente permite esse olhar mais liberto dos condicionamentos culturais que tradicionalmente separam os dois universos, o que torna possível a existência de analogias como essa de que falamos aqui, entre o "balaio" ou "cumbuco" a que se refere o cantador do sertão e a "caixa de Pandora" do mito grego. Permite também a Rosa enxergar, no canto do poeta popular do sertão, uma afinidade com certas convenções a partir das quais a poesia vem se realizando no decorrer dos tempos. Dessa forma, pode ver, na diversidade dos objetos do desejo da voz que se ouve no Coco, a expressão de sua (do desejo) abrangência; e, na repetição exaustiva da forma verbal "quero", a marca de sua intensidade; e, em tudo isso junto, o anseio pela "posse da totalidade, do absoluto, da simultaneidade e plenitude, eternas". 
A tradução do Coco, entretanto, não finaliza o assunto. Algumas cartas adiante, Bizzarri acaba por reconsiderar sua posição de usá-lo como epígrafe de "A estória de Lélio e Lina" e aceita outra sugestão de Rosa, a de transferi-lo para “Dão Lalalão". E, por fim, acaba por rever totalmente sua posição ao resolver publicar o Coco onde fora originalmente publicado no Brasil, como epígrafe de todo o livro, junto a Plotino e Ruysbroeck:

\begin{abstract}
Quanto ao famoso Coco, acho que V. tem todo o direito de xingar-me. Xingue à vontade e desabafe. Xingou? Bom, então posso falar: na revisão decidi voltar a colocar o Coco como epígrafe geral do livro. E sabe por quê? (Xingue de novo). Para equilibrar um pouco, com a colorida intuição popular, Plotino e Ruysbroeck, que deixados sozinhos, lá na frente, como égua madrinha, ameaçam dar ao leitor desprevenido e palpiteiro (a maioria dos leitores pertence à imensa legião dos palpiteiros, e a quase totalidade dos críticos literários) uma ideia totalmente errada da natureza poética das estórias. (Bizzarri; Rosa, 84. 15/01/1981).
\end{abstract}

Rosa e Bizzarri continuaram discutindo algumas questões relacionadas à publicação do $\mathrm{Coco},{ }^{12}$ mas essa última posição de Bizzarri demonstra como o relacionamento amigável e as conversas estimulantes e motivadoras contribuíram para o sucesso desse projeto de coautoria, na visão expressa pelo próprio Rosa, em que se envolveram autor e tradutor. Ao final, Bizzarri parece compreender o valor que Rosa emprestava ao ambiente em que decidiu localizar sua obra. Além de sua relação afetiva com sua terra natal, a adoção do sertão como espaço ficcional tem múltiplas funções na obra rosiana. A crítica rosiana tem demonstrado muitas delas, principalmente a que enfoca os elementos histórico-sociais a partir dos

12 Conversaram, por exemplo, sobre se deveriam incluir uma nota explicativa; ou se deveriam ser explorados “alguns 'ornatos' gráficos” em sua apresentação, como letras maiúsculas, grifos e itálicos. (Bizzarri; Rosa, 92-93. 07/02/1964).

Cad. Trad., Florianópolis, v. 41, no 2 p. 292-308, mai-ago, 2021. 
quais o sertão rosiano se constrói. Rosa também dá suas próprias explicações para essa escolha:

[...] eu tinha de escolher o terreno onde localizar as minhas histórias. Podia ser Barbacena, Belo Horizonte, o Rio, a China, o arquipélago de Neo-Baratária, o espaço astral, ou, mesmo, o pedaço de Minas Gerais que era mais meu. E foi o que preferi. Porque tinha muitas saudades de lá. Porque conhecia um pouco melhor a terra, a gente, bichos, árvores. Porque o povo do interior - sem convenções, 'poses' dá melhores personagens de parábolas: lá se veem bem as reações humanas e a ação do destino: lá se vê bem um rio cair na cachoeira ou contornar a montanha, e as grandes árvores estalarem sob o raio, e cada talo do capim humano rebrotar com a chuva ou se estorricar com a seca. (Rosa, Sagarana, 25).

\section{Referências}

Bizzarri, Edoardo; Rosa, Guimarães. João Guimarães Rosa: correspondência com seu tradutor italiano. 2 ed. São Paulo: T. A. Queiróz: Instituto Cultural Ítalo-Brasileiro, 1981.

Gomes, Angela de Castro. "Escrita de si, escrita da História: a título de prólogo". Escrita de si, escrita da História, Gomes, Angela de Castro (org.). Rio de Janeiro: Editora FGV, 2004. p. 7-24.

Guimarães, Júlio Castañon. Contrapontos: notas sobre correspondência no modernismo. Rio de Janeiro: Fundação Casa de Rui Barbosa, 2004. 
Machado, Marcia Regina Jaschke Machado. O modernismo dá as cartas: circulação de manuscritos e produção de consensos na correspondência de intelectuais nos anos de 1920. Tese de Doutorado, Faculdade de Filosofia, Letras e Ciências Humanas da Universidade de São Paulo. São Paulo, 260 p., 2012.

Moraes, Marcos Antonio de. "Afinidades eletivas". Correspondência Mário de Andrade \& Manuel Bandeira, Andrade, Mário de; Bandeira, Manuel. Organização, introdução e notas por Marcos Antonio de Moraes. 2. ed. São Paulo: Editora da Universidade de São Paulo, 2001, p. 13-33.

Nascimento, Edna Maria Fernandes dos Santos. "Gênese de uma obra e esboço de uma poética: a correspondência de João Guimarães Rosa”. Letras de Hoje. Porto Alegre: v. 49, n. 2, (2014): 163-171.

Pagès, Alain. "Correspondance et genèse". Leçons d'écriture: ce que disent les manuscrits, Grésillon, Almuth; Werner, Michaël (org.). Paris: Minard, 1985. p. 207-214.

Rosa, João Guimarães. Ficção Completa. Rio de Janeiro: Nova Aguilar, v. 1, 1994.

Rosa, João Guimarães. “Carta de João Guimarães Rosa a João Condé, revelando segredos de Sagarana”. Sagarana. Rio de Janeiro: Nova Fronteira, 2001.

Saraiva, Arnaldo. Conversas com escritores brasileiros. Porto: ECL, 2000.

Velloso, Mônica Pimenta. "Entre o sonho e vigília: o tema da amizade na escrita modernista". Tempo, Niterói, v. 13, n. 26, (2009): 205-224, 2009. DOI 10.1590/ S1413-77042009000100011. Disponível em: http://www.scielo.br/scielo. php?pid $=$ S1413-77042009000100011\&script $=$ sci_abstract\&tlng $=$ pt. $\quad$ Acesso em: 7 dez. 2020.

Viotti, Fernando Baião. "Em busca do indeterminado: Guimarães Rosa e seus tradutores". Teresa: revista de literatura brasileira. São Paulo, n. 8/9, (2008): 322-337. 
Zilly, Berthold. "'Procuro chocar e estranhar o leitor’: Grande Sertão: Veredas a poética da criação e da tradução”. Revista Fronteira Z: revista do Programa de Estudos Pós-Graduandos em literatura e crítica literária da PUC-SP. São Paulo: n. 19 , (2017): 4-31.

Recebido em: 11/12/2020

Aceito em: 10/03/2021

Publicado em maio de 2021

Claudia Soares. E-mail: claudiasoares3107@gmail.com. ORCID: https://orcid. org/0000-0001-7192-5092.

Márcia Regina Jaschke Machado. E-mail: marciaske@uol.com.br. ORCID: https://orcid.org/0000-0002-9667-8945. 